\title{
Complete Compensation in Skilled Reaching Success with Associated Impairments in Limb Synergies, after Dorsal Column Lesion in the Rat
}

\author{
John E. McKenna and lan Q. Whishaw \\ Department of Psychology and Neuroscience, University of Lethbridge, Alberta, Canada, T1K 3M4
}

\begin{abstract}
Each of the dorsal columns of the rat spinal cord conveys primary sensory information, by way of the medullary dorsal column nucleus, to the ventrobasal thalamus on the contralateral side; thus the dorsal columns are an important source of neural input to the sensorimotor cortex. Damage to the dorsal columns causes impairments in synergistic proximal or wholebody movements in cats and distal limb impairments in primates, particularly in multiarticulated finger movements and tactile foviation while handling objects, but the behavioral effects of afferent fiber lesions in the dorsal columns of rodents have not been described. Female Long-Evans rats were trained to reach with a forelimb for food pellets and subsequently received lesions of the dorsomedial spinal cord at the C2 level, ipsilateral to their preferred limb. Reaching success completely recovered within a few days of dorsal column lesion. Neverthe-
\end{abstract}

Primary and postsynaptic afferent fibers ascend ipsilaterally within the dorsal column tracts to the cuneate and gracile nuclei, which transfer sensory information primarily to the contralateral ventrobasal thalamus and somatosensory cortex. Damage to the ascending dorsal columns compromises fine motor skills in humans (Nathan et al., 1986; Gordon et al., 1995) and other primates (Vierck, 1978; Leonard et al., 1992; Cooper et al., 1993), principally by interfering with movement of the distal musculature ipsilaterally (Vierck, 1978; Sanes et al., 1985; Glendinning et al., 1993; Gordon et al., 1995; Galea and Darian-Smith, 1997); thus the dorsal columns are considered an essential anatomical substrate of dexterous movement in these species. In the cat, dorsal column lesions have been described as disrupting synergistic movements used in complex "predatory-like" behavior (Dubrovsky et al., 1971). Surprisingly, there have been no detailed behavioral studies of the effects of lesions of dorsal column sensory fibers on forelimb usage in rats, although dorsal column damage has been included in studies using larger, less selective lesions (Saling et al., 1992; Schrimsher and Reier, 1992, 1993; Diener and Bregman, 1998a).

The effects of dorsal column lesions in the rat are of considerable interest because (1) the rat is capable of skilled limb and digit movements used in prehension (Brácha et al., 1990; Whishaw and Pellis, 1990; Whishaw et al., 1992a,b; Whishaw and Gorny, 1994);

\footnotetext{
Received Sept. 9, 1998; revised Nov. 17, 1998; accepted Dec. 21, 1998.

This work was supported by the Medical Research Council of Canada (I.Q.W.) and the Alberta Heritage Foundation for Medical Research (J.M.).

Correspondence should be addressed to Dr. Ian Q. Whishaw, Department of Psychology and Neuroscience, University of Lethbridge, Lethbridge, Alberta, T1K 3M4 Canada.

Copyright (ㄷ) 1999 Society for Neuroscience $\quad 0270-6474 / 99 / 191885-10 \$ 05.00 / 0$
}

less, a detailed analysis of high-speed video recordings revealed that rotatory limb movements (aiming, pronation, supination, etc.) were irreversibly impaired. Compensation was achieved with whole-body and alternate limb movements. These results indicate the following: (1) in the absence of the dorsal columns, other sensorimotor pathways support endpoint success in reaching; (2) sensory input conveyed by the dorsal columns is important for both proximal and distal limb movements used for skilled reaching; and (3) detailed behavioral analyses in addition to endpoint measures are necessary to completely describe the effects of dorsal column lesions.

Key words: dorsal column; lesion; skilled movement; recovery of function; forelimb; food handling; reaching; spinal cord; injury; rat

(2) it has a well developed sensorimotor system, such that different aspects of these skilled forelimb movements are disturbed by lesions of the motor cortex (Castro, 1972; Whishaw et al., 1991; Saling et al., 1996), the pyramidal tract (Whishaw et al., 1993; Z'Graggen et al., 1998), the caudate-putamen (Whishaw et al., 1986), or the red nucleus (Whishaw and Gorny, 1996; Whishaw et al., 1998); and (3) because it is widely used for the study of recovery of function (Kosinski et al., 1987; Neafsey et al., 1989; Schallert and Lindner, 1990; Castro et al., 1991), especially in models in which the spinal cord is damaged ( $\mathrm{Li}$ and Raisman, 1994; Cheng et al., 1996; Bregman et al., 1997; Christensen and Hulsebosch, 1997; Schwab and Brosamle, 1997; Diener and Bregman, 1998a,b; Keirstead et al., 1998; Rapalino et al., 1998).

The purpose of the present experiment is threefold: (1) to determine the behavioral consequences of dorsal column lesions in rats, within a model of skilled forelimb use that requires accurate reaching for single food pellets; (2) to examine specific behaviors during pellet reaching and determine the behavioral components that are correlated with reaching success; and (3) to examine the behavior of animals in which damage was done to other fiber systems, to control for the effects of nonspecific spinal cord damage.

\section{MATERIALS AND METHODS}

\section{Subjects}

Subjects were 16 adult female Long-Evans hooded rats, raised at the University of Lethbridge vivarium, that weighed $200-250 \mathrm{gm}$ at the beginning of the experiment. Rats were housed in hanging wire mesh cages (four animals per cage) in an animal colony lighted on a $12 \mathrm{hr}$ light/dark cycle, lights off at 7 P.M. Training and testing were performed during the lighted portion of the cycle. Rats were food-deprived to $90 \%$ of normal body weight and received measured amounts of food once a 

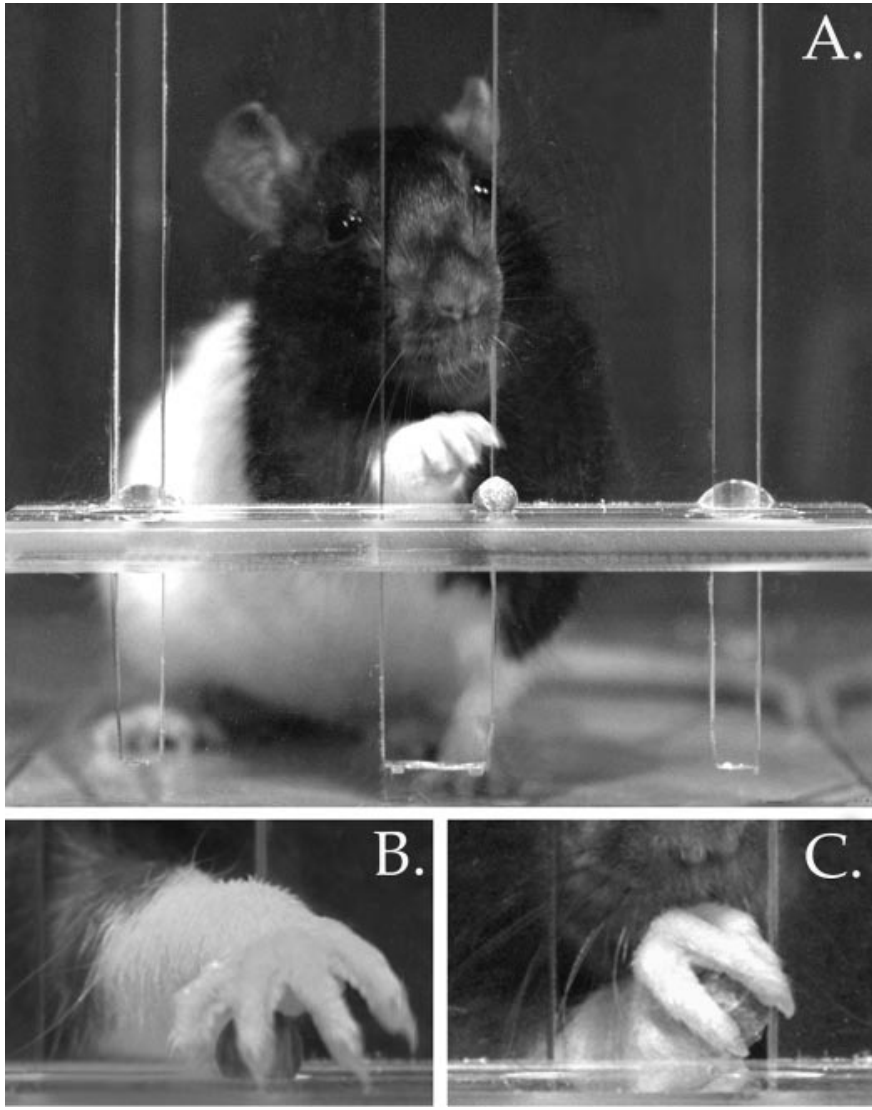

Figure 1. A, Frontal view of a rat advancing its limb through the slot of the pellet reaching apparatus. $B$, Close-up view of a control rat's paw fully pronated over a food pellet, with digits 4 and 5 beginning to grasp the pellet. $C$, View of the rat's paw being supinated as it is withdrawn through the slot.

day to maintain body weight and deprivation state. All rats were trained in the pellet-reaching task (Whishaw and Pellis, 1990) before surgery.

\section{Surgery}

Each rat was lightly anesthetized before surgery with sodium pentobarbitol $(40 \mathrm{mg} / \mathrm{kg})$ and atropine methyl nitrate $(5 \mathrm{mg} / \mathrm{kg})$; a mixture of isofluorine and oxygen was administered during surgery to achieve deep anesthesia. A sagittal incision was made at the nape of the neck, and with the aide of an operating microscope, blunt dissection revealed the dorsal surface of the first and second cervical vertebrae. The mediocaudal part of the $\mathrm{C} 1$ vertebra was removed with rongeurs, so that the dorsal column tract on one side of the spinal cord was made visible and could be incised with a sharp No. 11 scalpel blade. The skin incision was closed with wound clips, and the animal was warmed under a heat lamp until it recovered consciousness.

\section{Observation box for skilled reaching}

Animals were trained and tested inside a clear Plexiglas box $(40 \times 40 \times$ $12.5 \mathrm{~cm}$ wide) mounted on a stand above an inclined mirror, so that they could be filmed from any perspective (Fig. 1). In the center of the front wall was a 1-cm-wide slit that extended from $1 \mathrm{~cm}$ above the floor to a height of $20 \mathrm{~cm}$. A shelf $(10 \times 3.5 \mathrm{~cm}$ wide $)$ was attached to the outside of the front wall, at a height of $3 \mathrm{~cm}$ above the floor. Two small indentations in the shelf served as wells to hold food pellets. These were aligned with the edges of the slit and were located $2 \mathrm{~cm}$ from the inside of the front wall of the box. This design prevented rats from retrieving food pellets with their tongues and required them to reach with one forelimb through the slit for a food pellet located in the contralateral food well and then pronate medially over the food to grasp it (Whishaw and Gorny, 1994). Rats were individually trained and allowed to reach with their preferred forelimb for food pellets (94 mg Rodent Chow pellets, Bioserve Inc.)

\section{Video recording}

Video recordings were made at 120 frames/sec, with a Peak 120 high speed video camera (Peak Performance Technologies, Englewood, CO) on VHS magnetic tape. A frame grabber was used to capture individual fields for analysis.

\section{Training and testing}

All animals were trained before surgery to retrieve food pellets in the reaching box. Each animal was videotaped from frontal, lateral, and ventral perspectives while retrieving food pellets. Each training session began with food pellets being placed in both wells, so that the animal could attain food with either forelimb. Whichever food well was first visited was noted, and food pellets were supplied on that side only, for the duration of the training session. This served as a check that animals were being trained to reach with their preferred forelimb. All animals quickly developed a tendency to reach for pellets with only one forelimb.

\section{Success ratings}

To quantify the accuracy of each animal's reaching, sequential behavioral observations were rated. Whenever a pellet was present in a food well, the animal's first limb extension through the slot of the reaching box was evaluated. If the pellet was successfully grasped and brought back through the slot to the rat's mouth, then the reach was scored as a hit. If the rat failed to grasp the food, or if it dropped the food, then the reach was scored as a miss. If the rat extended its forelimb through the opening without attempting to grasp the pellet (e.g., to touch the pellet before picking it up), the reach was not counted. To provide a behavioral measure of success, the percentage of successful reaches was calculated for each animal.

\section{Movement analysis}

Reaching movements were rated using a series of rating scales derived from Eshkol-Wachman movement notation (Eshkol and Wachman, 1958). The scales measure (1) whole-body movements of orienting, in which the rat locates the food item by sniffing; (2) postural adjustments, involving bodily alignment with the targeted food well, and support of body mass being shifted primarily onto the nonreaching forelimb and diagonal hind limb; (3) a series of $10 \mathrm{arm}$ and paw movements; and (4) arpeggio movements, in which the paw is positioned over the food item (Whishaw and Pellis, 1990; Whishaw et al., 1991, 1992a,b).

Target localization. Target localization was rated on a three-point scale. If a rat inserted its nose into the slot, oriented the tip of its snout to the food, and sniffed, it received a score of 0 (i.e., normal). If these movements were recognizable but abnormal, they were given a score of 1 ; if a rat failed to make these movements, it received a score of 2 (Whishaw and Tomie, 1989).

Body rotation ratings. Abnormalities in body posture that involved rotational compensation were rated by means of a three-point scale. Normal posture (given a score of 0 ) consisted of a stable diagonal stance maintained from the limb lift through to the first supination movement (i.e., the contralateral forelimb and ipsilateral hindlimb supported the animal during the reach), vertical head movement as the forepaw is advanced, and independent rotatory movements of the shoulder and elbow musculature during first and second supination movements. A score of 1 was given if the body was rotated slightly to assist the forepaw movements. A score of 2 was given if gross rotational movements were evident.

Ten component ratings. Qualitative aspects of each animal's reaching movements were analyzed by means of a previously described rating scale (Whishaw et al., 1993) applied to each of the following 10 component movements: (1) limb lift: the limb is lifted from the floor by the upper arm and the digits are swung to the body's midline; (2) digits close: as the limb is lifted, the digits are semiflexed, and the paw is supinated so that the palm faces the midline of the body; (3) aim: the elbow is adducted by the upper arm so that the forearm and digits are aligned with the body's midline, and the paw is held just under the mouth (this seems to require a counter-rotation about the wrist, to offset the elbow adduction); (4) advance: the head is lifted, and the limb is advanced above and beyond the pellet; (5) digits open: the digits are extended and opened as the limb is advanced; (6) pronate: the elbow is abducted by the upper arm, and the paw is pronated over the food; (7) grasp: as the palmar pads touch the food, the digits close around it, and closure can occur before or during paw withdrawal; (8) supination I: as the paw is withdrawn, it is dorsiflexed and supinated $90^{\circ}$ by a movement around the wrist and by 
adduction of the elbow; (9) supination II: as the rat sits back on its haunches, the paw is supinated by a further $90^{\circ}$ and is ventroflexed so that the food is brought up to its mouth; and (10) release: the digits are opened and the food is transferred to the mouth.

Videotape footage of five successful reaches by each rat was analyzed to rate the quality of each of these 10 movements on a three-point scale. If the movement appeared normal, it was given a score of 0 ; if the movement was somewhat abnormal but recognizable, it was given a score of 1 ; and if the movement was absent or was compensated for entirely by moving another part of the body, it was given a score of 2 .

Videotape footage of successful reaches was also examined frame by frame, and stick diagrams were produced to help summarize (schematically) the movements made by rats during skilled reaching and to facilitate quantification of changes in forelimb movements. For each video frame, a line segment was drawn connecting the tips of digits 2 and 5 to indicate their position relative to the center of the food pellet (represented by a dot); however, if digit 5 was not clearly visible throughout a movement sequence, then digits 2 and 4 were used as reference points. Line segments were then placed in register so that movement of the paw relative to the pellet could be analyzed further. The first line in each stick diagram was denoted by an arrowhead to facilitate interpretation of the temporal order of summarized movements.

Arpeggio ratings. Arpeggio movements were analyzed by examining close-up frontal views of pellet retrieval, videotaped at 120 frames/sec. Briefly, an arpeggio movement consists of the rat's paw being pronated onto the shelf so that digits 5 through 2 consecutively contact the shelf. This enables the animal to palpate the surface of the shelf to ascertain the precise location of the food pellet (Whishaw and Gorny, 1994). This reaching movement was rated on a three-point scale. If the arpeggio movement appeared normal, it was given a score of 0 ; if the movement was abbreviated somewhat but was recognizable, it was given a score of 1 ; if the arpeggio movement was absent, the movement was given a score of 2.

\section{Histology}

When behavioral testing was completed, each rat was deeply anesthetized and perfused intracardially with solutions of $0.9 \% \mathrm{NaCl}$ and $4 \%$ paraformaldehyde. The brain and spinal cord were removed, photographed, and post-fixed in a $30 \%$ sucrose $/ 4 \%$ paraformaldehyde solution. The cervical spinal cord was blocked into $15 \mathrm{~mm}$ specimens, frozen, and cut into $60 \mu \mathrm{m}$ sections. Sections were mounted on glass sides, stained with Cresyl violet, and coverslipped.

\section{Statistical analysis}

Pellet retrieval data (evaluated on a ratio scale) were subjected to ANOVA tests and, when appropriate, probed further with NewmanKeuls post hoc tests (Winer, 1962). Movement abnormality scores (rated on an ordinal scale) were investigated with Kruskal-Wallis $H$ tests and, when appropriate, evaluated further by means of Mann-Whitney $U$ tests (Ferguson, 1971). Data were examined with a computerized statistical package (Statview, Abacus Concepts, Berkeley, CA). Significance levels were established at $p<0.05$ for planned comparisons and $p<0.01$ for post hoc tests.

\section{RESULTS}

\section{Histology}

Histological examination revealed that on the side of the spinal cord ipsilateral to the animals' preferred paws, lesions of five animals were restricted to the dorsomedial portion of the white matter, with minimal damage to the dorsal horn; five animals sustained damage to the dorsolateral portion of the spinal cord, including the dorsolateral fasciculus and layers $\mathrm{I}-\mathrm{V}$ of the dorsal horn; and four animals had damage to both dorsomedial and dorsolateral portions of the white matter. In all 16 cases, there was minimal or no damage to the corticospinal tract. Lesions of two additional animals were made on the side of the spinal cord contralateral to the preferred forepaw: one located dorsomedially and one located dorsolaterally. Figure 2 illustrates the approximate location of the forelimb afferent fibers within the dorsal column tract (Arvidsson and Pfaller, 1990; Paxinos and Watson, 1997) along with representative photomicrographs of a dorsal
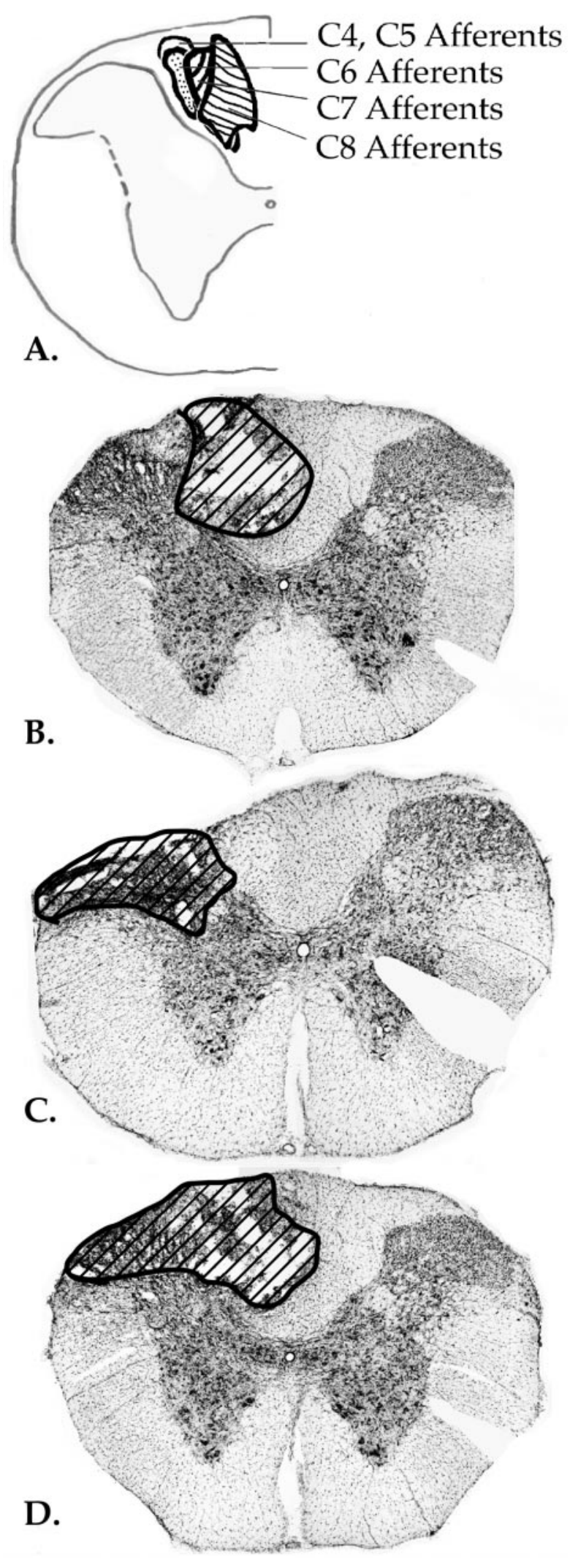

Figure 2. A, Schematic diagram of the location of forelimb afferent fibers ascending in the dorsal column tract of the cervical spinal cord (Arvidsson and Pfaller, 1990). B, Photomicrograph of a representative dorsal column lesion. $C$, Photomicrograph of a representative dorsolateral lesion. $D$, Photomicrograph of a combined lesion, with damage of dorsomedial and dorsolateral parts of the cervical spinal cord. 


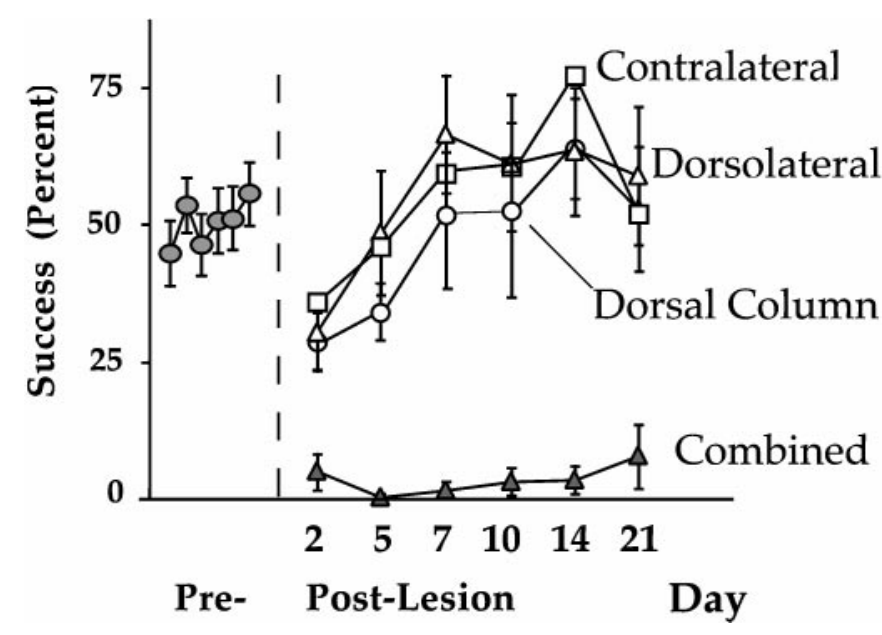

Figure 3. Skilled reaching performance (SEM) of successful food pellet retrieval after dorsal column, dorsolateral, combined dorsomediolateral, or contralateral dorsal column myelotomies.

column lesion, a dorsolateral lesion, and a combined lesion (that damaged both medial and lateral aspects) of the cervical spinal cord. Animals were grouped for statistical analysis according to the location of spinal cord damage.

\section{Success ratings}

Pellet retrieval rates of the four lesion groups were compared during the six reaching sessions before surgery, and no significant differences in success rates were indicated $\left(F_{(3,12)}=0.43 ; p=\right.$ NS). Although there was a trend toward slightly higher pellet retrieval rates across the six test sessions, the trend was not statistically significant $\left(F_{(5,60)}=2.17 ; p=0.07\right)$. A mean success rate was then calculated for each animal to be used as a baseline for subsequent comparisons with post-lesion pellet retrieval. Rates of successful pellet retrieval were compared among the four lesion groups at six time points during their recovery period. Each animal's reaching success was compared with its baseline rate $2,4,7,10,14$, and $21 \mathrm{~d}$ after spinal cord injury.

A repeated-measures ANOVA found a main effect of lesion group $\left(F_{(3,12)}=4.08 ; p=0.03\right)$ and a main effect of time of testing $\left(F_{(6,72)}=8.46 ; p=0.0001\right)$. This showed quantitatively that the spinal cord lesions affected skilled reaching in all cases compared with baseline levels and that retrieval success changed over time. An interaction among the two factors $\left(F_{(18,72)}=3.59 ; p=\right.$ 0.0001 ) showed that recovery rates were not the same for all groups (Fig. 3). Newman-Keuls post hoc tests revealed that the interaction was caused by the significantly poorer performance by the combined lesion group, after day 5. These statistics indicate that by post-lesion day 7 , the dorsal column, dorsolateral, and contralateral lesion groups' pellet retrieval success rates had returned to baseline levels, whereas the combined lesion group's success rates remained well below baseline levels for the duration of the experiment (Fig. 4A).

\section{Movement analysis}

\section{Target localization}

There were no group differences in target localization because rats in all groups inserted their noses into the slot and sniffed the food pellet before reaching for it.

\section{Body rotation ratings}

When ratings of abnormal postural rotations were compared, a significant difference among the five groups was indicated $\left(H_{4}=\right.$
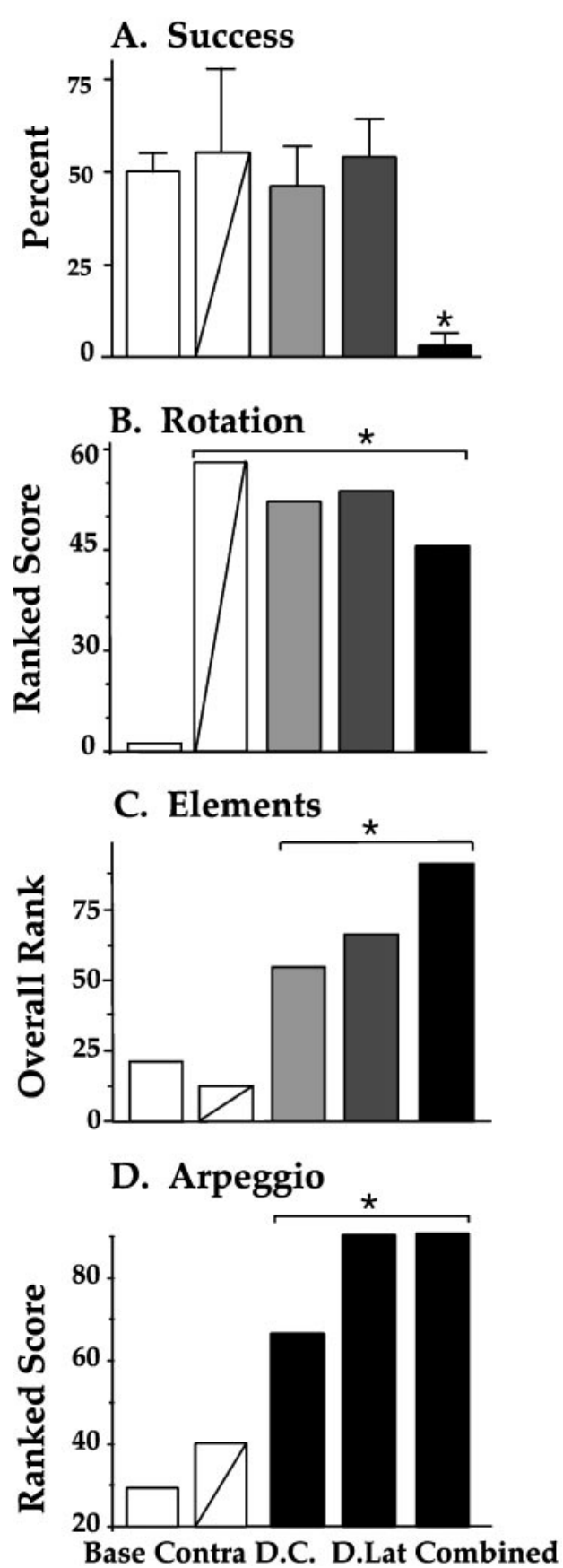

Figure 4. Performance ratings of skilled reaching for single food pellets. $A$, Percentage of grasps that were successful (SEM). B, Rating of compensatory body rotations. $C$, Summary ratings of abnormality scores on the 10 movement elements that comprise a reach. $D$, Arpeggio ratings, which rate the independent placement of digits onto the shelf before the food pellet is grasped. * = difference from baseline; $p<0.01$.

56.2; $p=0.0001)$. Post hoc tests showed that all of the lesion groups were significantly different from the baseline control group in their use of compensatory rotatory movements; this is apparent in Figure $4 B$. Abnormal torsion of the head and neck, dropping the ipsilateral shoulder, and gross rotatory movements of the trunk, hindlimbs, and nonpreferred forelimb during pronation and supination of the preferred forelimb were the most commonly observed compensatory movements (Fig. 5). 


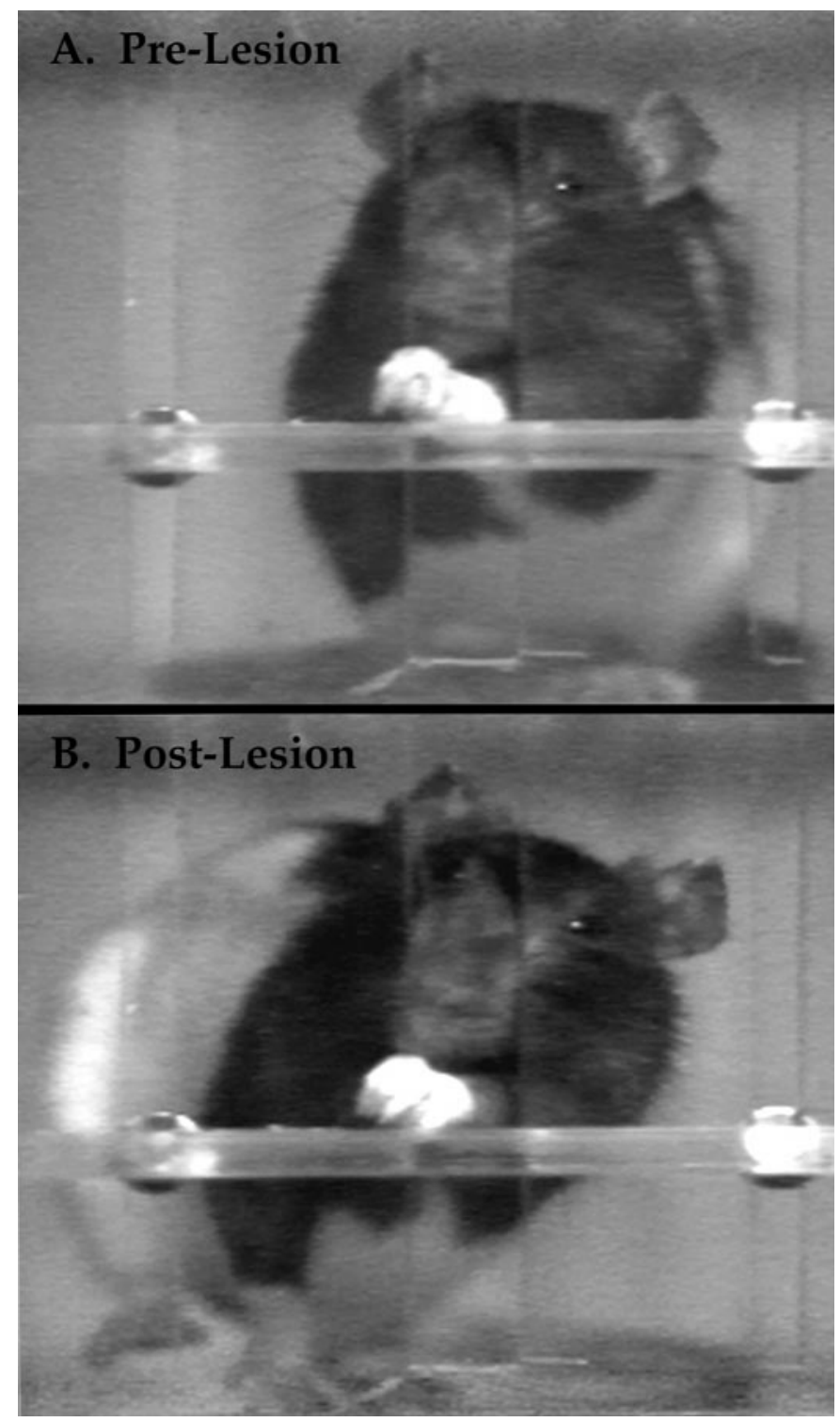

Figure 5. Rotatory changes in body posture observed after dorsal column lesion.

\section{Ten component ratings}

To assess the extent to which reaching elements were changed, relative to preoperative movements, by each of the four types of spinal cord lesions, the 10 reaching element data were subjected to a Kruskal-Wallis analysis. A comparison of the summed reaching element scores revealed that the five groups were heterogeneous $\left(H_{4}=83.7 ; p=0.0001\right)$, as is illustrated in Figure $4 C$. When pair-wise comparisons were made among the five groups, the three ipsilateral lesion groups were each found to be significantly different from each other, as well as from the contralateral lesion group and the preoperative control group (Table 1).

Abnormality scores on each of the 10 reaching components were compared among the five groups and are presented in Table 2. All three ipsilateral lesion groups had significantly more abnormalities in lift, aim, pronation, grasp, and supination movements than either the contralateral lesion group or the baseline controls; however, the dorsolateral and combined lesion group's scores were significantly higher than the dorsal column group's
Table 1. $Z$-score comparisons of overall movement abnormality ratings

\begin{tabular}{|c|c|c|c|c|}
\hline Group & $\begin{array}{l}\text { Dorsal } \\
\text { column }\end{array}$ & Dorsolateral & $\begin{array}{l}\text { Dorsal } \\
\text { and lateral }\end{array}$ & $\begin{array}{l}\text { Contra- } \\
\text { lateral }\end{array}$ \\
\hline Dorsolateral & $2.65^{*}$ & & & \\
\hline Dorsal and lateral & $5.37 * *$ & $4.92 * *$ & & \\
\hline Contralateral & $4.58^{* *}$ & $4.57^{* *}$ & $4.62 * *$ & \\
\hline Baseline & $5.78^{* *}$ & $5.75^{* *}$ & $5.74 * *$ & 1.95 \\
\hline
\end{tabular}

Pair-wise comparisons of summary ratings of 10 reaching component abnormalities after different $\mathrm{C} 2$ spinal cord lesions. Differences between lesion groups are signified by ${ }^{*} p \leq 0.01$ and ${ }^{* *} p \leq 0.0001$.

Table 2. Movement abnormality ratings (mean ranked scores)

\begin{tabular}{|c|c|c|c|c|c|}
\hline Group & $\begin{array}{l}\text { Pre- } \\
\text { operation }\end{array}$ & $\begin{array}{l}\text { Contra- } \\
\text { lateral }\end{array}$ & $\begin{array}{l}\text { Dorsal } \\
\text { column }\end{array}$ & Lateral & $\begin{array}{l}\text { Dorsal and } \\
\text { lateral }\end{array}$ \\
\hline \multicolumn{6}{|l|}{ Behavior } \\
\hline Lift & 26 & 22 & $50^{*}$ & $70^{* *}$ & $73^{* *}$ \\
\hline \multicolumn{6}{|l|}{ Digits } \\
\hline flexed & 52 & 52 & 52 & 52 & 52 \\
\hline Aim & 26 & 20 & $49^{*}$ & $67^{* *}$ & $79^{* *}$ \\
\hline Advance & 40 & 38 & 44 & 48 & $84^{* *}$ \\
\hline \multicolumn{6}{|l|}{ Digits } \\
\hline open & 42 & 42 & 42 & 46 & 51 \\
\hline Pronate & 24 & 14 & $53^{* *}$ & $65^{* *}$ & $64^{*}$ \\
\hline Grasp & 24 & 22 & $56^{* *}$ & $60 * *$ & $63^{* *}$ \\
\hline Supinate I & 25 & 23 & $57^{* *}$ & $59^{* *}$ & $62^{*}$ \\
\hline Supinate II & 22 & 21 & $59^{* *}$ & $57^{* *}$ & $63^{* *}$ \\
\hline $\begin{array}{l}\text { Pellet re- } \\
\text { lease }\end{array}$ & 36 & 36 & 41 & 40 & $56^{*}$ \\
\hline \multicolumn{6}{|l|}{ Overall rank/ } \\
\hline 104 & 21 & 13 & $55^{* *}$ & $66^{* *}$ & $92 * *$ \\
\hline
\end{tabular}

Group ratings of 10 reaching components before and after spinal cord lesions. For each movement, $0=$ normal; $1=$ movement is abnormal but recognizable; $2=$ movement is absent or entirely compensated for by movement of another body part. Differences from controls are signified by ${ }^{*} p \leq 0.001$ and $* * p \leq 0.0001$.

scores for lift $\left(Z_{(23,24)}=2.9\right.$ and 3.1, respectively; $\left.p<0.01\right)$ and $\operatorname{aim}\left(Z_{(20,24)}=2.6, p<0.01\right.$, and $\left.Z_{(18,20)}=4.1, p<0.0001\right)$. Additionally, the combined lesion group advanced the forelimb abnormally and released food pellets abnormally, compared with any other group.

\section{Arpeggio ratings}

When arpeggio abnormality ratings were compared, a difference among all groups was indicated $\left(H_{4}=78.6 ; p=0.0001\right)$. As is evident in Figure $4 D$, dorsolateral and combined lesions caused the greatest changes in arpeggio movements $\left(Z_{(24,39)}=6.7\right.$ and 6.1 , respectively; $p=0.0001)$. Dorsal column lesions also caused significantly higher arpeggio ratings, compared with baseline $\left(Z_{(24,40)}=5.0 ; p=0.0001\right)$ or contralateral lesions $\left(Z_{(9,24)}=2.3\right.$; $p=0.02)$ but were less severe than the dorsolateral $\left(Z_{(24,24)}=\right.$ $3.9 ; p=0.0001)$ or combined $\left(Z_{(19,24)}=3.2 ; p=0.001\right)$ lesions.

Figure $6 A$ depicts the advance portion of a reaching sequence by a normal animal. In the first frame, digits 1 and 2 are aligned with the center of the snout during the aim, and the first line in the stick diagram (denoted by the arrowhead) shows that the animal's paw is at a $44^{\circ}$ angle to the shelf as it passes through the aperture. In the second frame, the limb is advanced and raised slightly, at an angle of $47^{\circ}$ (the digits are spreading, as is indicated by the longer line segment in the stick figure). In the third frame, the beginning of the arpeggio movement can be seen as all digits 


\section{Advance}

\section{A.}
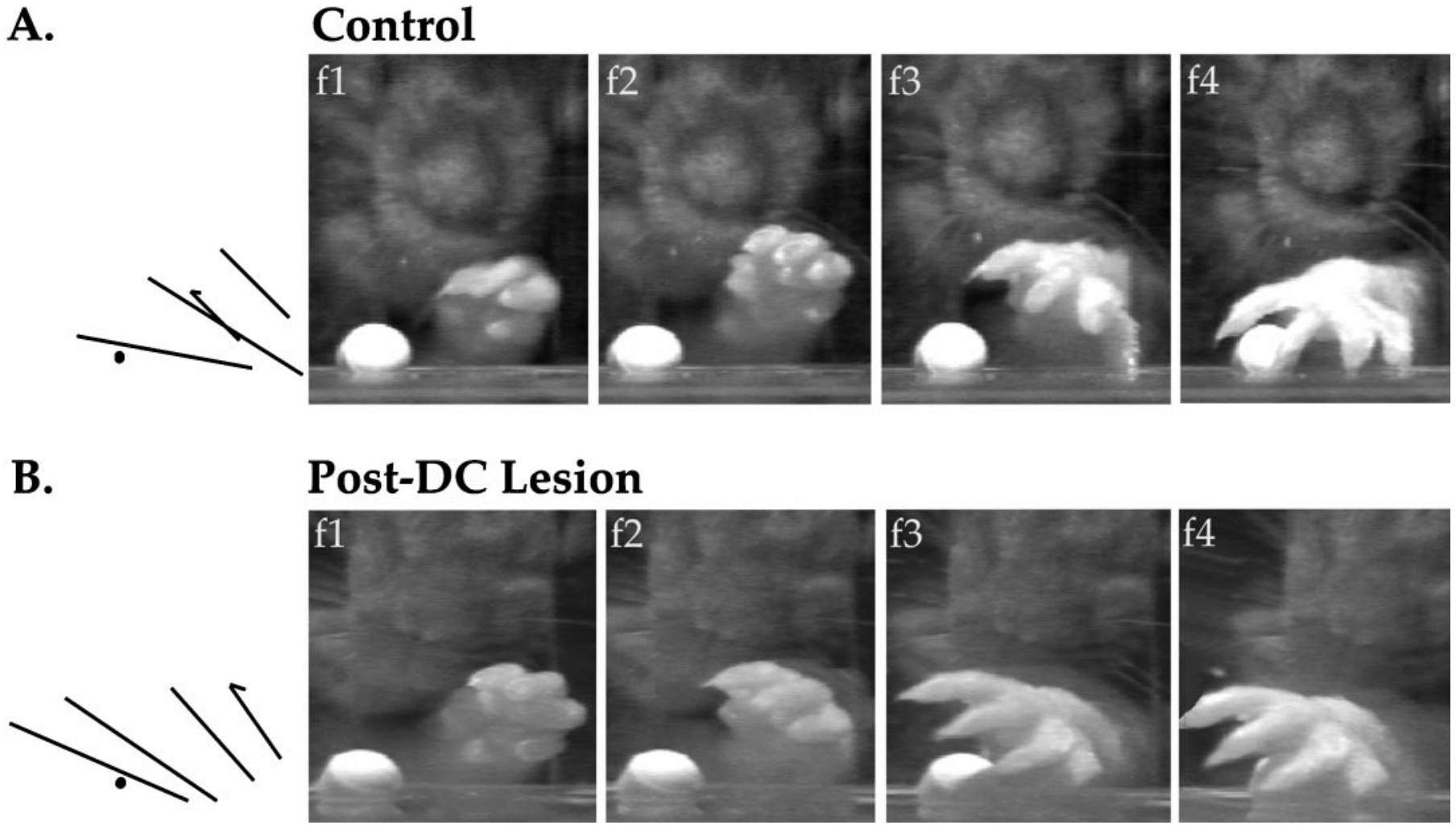

Figure 6. Paw positions and paw withdrawal sequence before $(A)$ and after $(B)$ lesion. Stick figures on the left illustrate digit positions on successive frames.

are fully extended, digit 5 is in contact with the shelf, and the paw is being pronated over the pellet (paw angle is $33^{\circ}$ ). In the fourth frame, the end of the arpeggio movement is visible (digits 3,4 , and 5 are widely spaced and in contact with the shelf, the paw angle is $7^{\circ}$, and digit 2 is straddling the pellet).

In contrast, Figure $6 B$ shows the advance portion of a reaching sequence by a dorsal column-lesioned rat. In the first frame, the limb is not aligned with the snout during the aim, and the paw is at a $57^{\circ}$ angle as it emerges through the aperture. In the second frame, the limb is advanced toward the pellet in a lateral sweeping motion, with the digits semiflexed. In the third frame, the sweeping motion continues, and the digits are fully extended but very little pronation is evident (paw angle is $37^{\circ}$ ). In the fourth frame, the pellet is cradled by digits 4 and 5 , no further pronation has occurred (paw angle is still $37^{\circ}$ ), and only digit 5 is in contact with the shelf.

Figure $7 A$ depicts the withdrawal portion of a reaching sequence by a normal animal. In control frame $5(f 5)$, digits 2 and 3 grasp the food pellet out of the food well; the paw angle is $12^{\circ}$. In frames 8 and 10, the paw is supinated to angles of $50^{\circ}$ and $79^{\circ}$, respectively. In frame 14, the paw is further supinated to an angle of $120^{\circ}$ as the pellet is brought to the mouth. In contrast, Figure $7 B, f 5$ shows a dorsal column-lesioned rat grasping the food pellet by swiftly closing its paw while the paw is at an angle of $53^{\circ}$. In frame 8 , the lesioned animal seems to supinate its paw to an angle of $72^{\circ}$; however, this paw movement is achieved by rotating the shoulder ventrally, as is indicated by the lower position of the animal's head (note the changing position of the dark pigmented region above the whiskers, across the four frames, and the appearance of the eye in the top right corner of frames 14 and 15). Finally, in frame 15, the paw drops from the shelf as it is pulled back through the aperture, instead of being raised toward the mouth. The lesioned rat then consumes the food pellet by lowering its head and uses the other paw to raise and supinate the affected paw. These observations indicate that the weight of the limb was previously supported by the shelf rather than by the affected forelimb musculature.

Dorsal column lesion, therefore, causes major changes in the movements used for skilled reaching. Pronation is greatly reduced, and independent supination does not occur. The speed of grasp is also increased after dorsal column lesion. Note that although the lesioned animal has the pellet tightly grasped and elevated for $120 \mathrm{msec}$ (i.e., one frame) after initial contact with the pellet, the normal animal does not achieve a similar paw position until $360 \mathrm{msec}$ (i.e., three frames) after contact. Finally, despite the increased speed of pellet grasping, the lesioned animal is impaired in its ability to complete the reaching sequence. Because the affected limb drops below the shelf and the head is lowered to consume the food, a lesioned animal takes much longer to bring the pellet to its mouth for consumption (e.g., in the sequence shown after lesion, the rat did not manage to get the food to its mouth until an additional $1080 \mathrm{msec}$ (i.e., nine video frames) had passed.

The video sequence shown in Figure 8 illustrates the lack of arpeggio movement in a dorsolateral-lesioned rat. In frames 3, 5, 8 , and 9 , the animal raises its forepaw two to three times higher 


\section{Withdraw}

A.

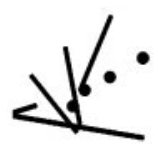

B.

\section{Control}
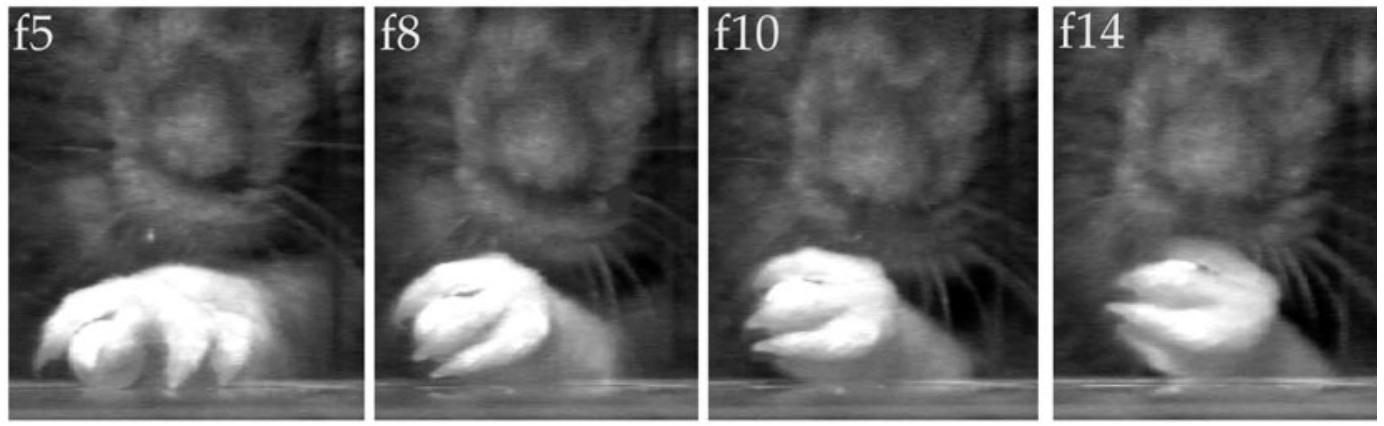

\section{Post-DC Lesion}

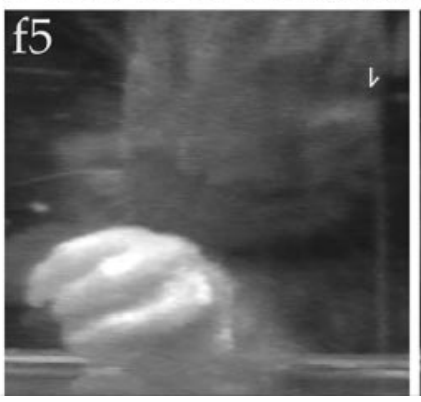

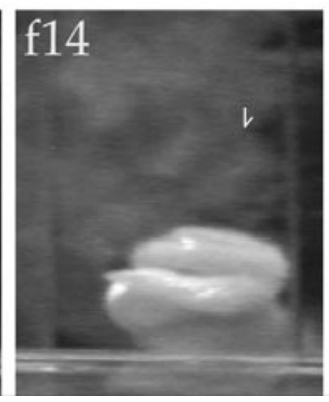

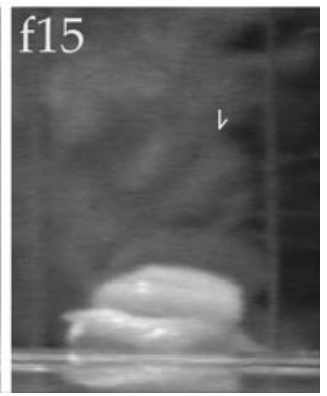

Figure 7. Paw positions and paw advance sequence before $(A)$ and after $(B)$ dorsal column lesion. Stick figures on the left illustrate digit positions on successive frames.

\section{Limb Advance After Dorsolateral Lesion}
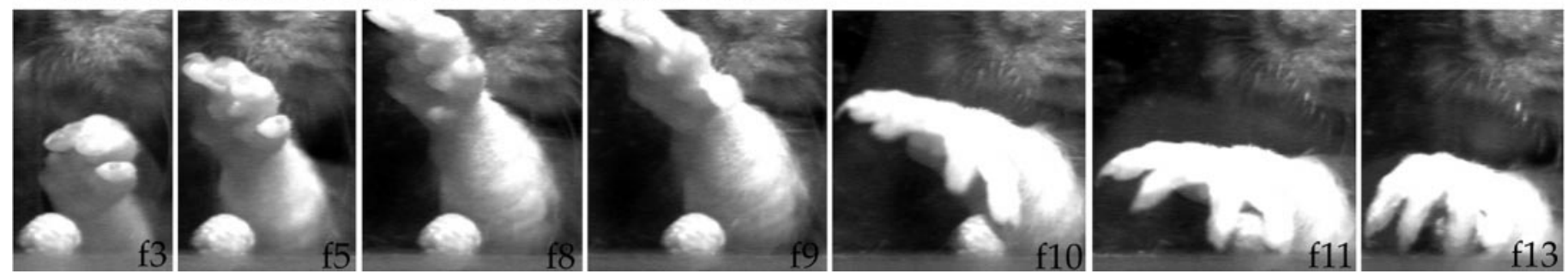

Figure 8. Paw advance sequence after dorsolateral spinal cord lesion.

than a normal animal (compare with Fig. 6A) and extends and spreads its digits wide. It then simply drops the paw onto the food pellet in frames 10 and 11 and grasps the pellet loosely in frame 13. The animal subsequently exhibited difficulties in supination similar to those described for dorsal column-lesioned animals.

\section{Reaching when food was absent}

Videotape recordings of reaches made by animals when no food was present on the tray were also examined. Figure 9 (top row) illustrates a typical reach sequence made by a control rat when no food pellet was present on the tray. When the empty food well was encountered, the rat made a sweeping motion with its outstretched digits while palpating the tray surface with its palmar pads. After this manual search was performed and no food pellet was encountered, the control animal withdrew its paw without effecting a grasping movement (total search $=2.76 \mathrm{sec}$ ). Figure 9 (bottom row) shows that after dorsal column lesion, the affected forepaw made less contact with the food tray when the food well was empty, searching movements were absent, and the paw snapped shut as soon as any digit came into contact with the food well (total search $=0.84 \mathrm{sec}$ ).

\section{DISCUSSION}

This is the first detailed analysis of the effects of selective dorsal column lesion in the rat, a species widely used for studies of recovery of function from spinal cord damage. Rats were trained to reach through an aperture and retrieve single small food pellets located on a shelf. Presurgically, the rats were proficient at pellet retrieval, and after selective dorsal column lesion, the rats' reaching success with their ipsilateral paws quickly recovered to baseline levels. Nevertheless, an examination of high-speed video records of the rats' performance revealed that the animals used different movement sequences to retrieve the food pellets after 


\section{Pre-Lesion Search}
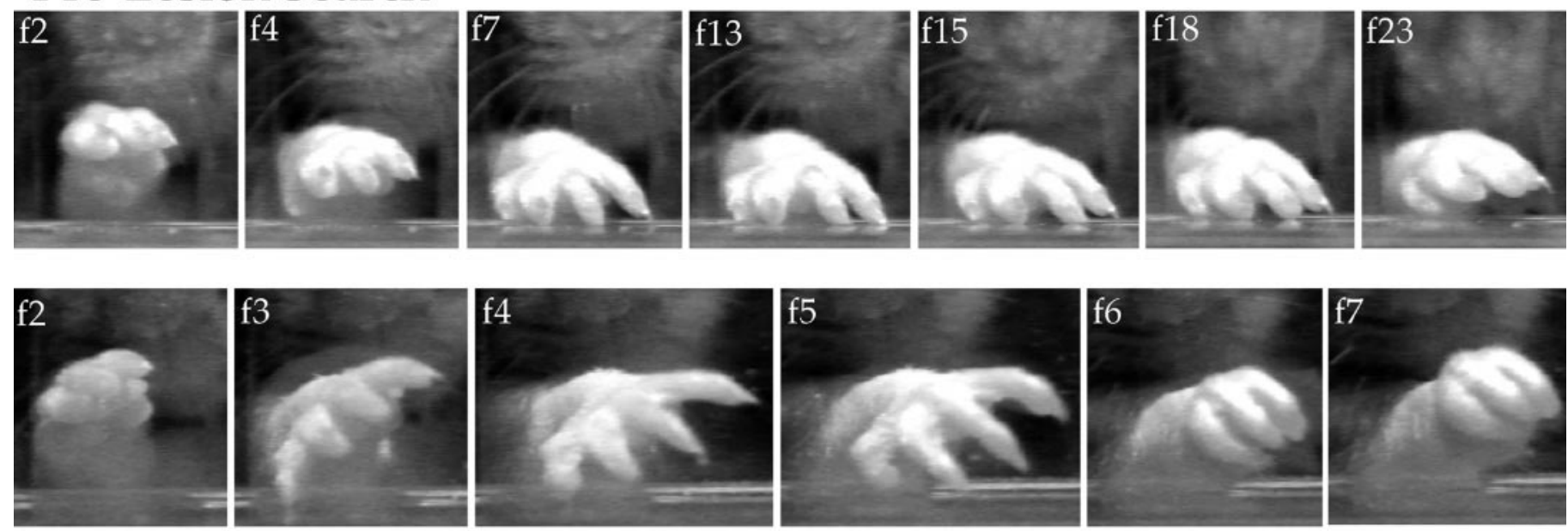

\section{Post-Lesion Search}

Figure 9. Exploratory movement sequences observed when no food pellet was present before (top) and after (bottom) dorsal column lesion.

surgery. These results show that afferent fibers in the dorsal columns normally contribute to skilled forelimb use in the rat as they do in other species.

Many of the rats' movements were irreversibly changed after dorsal column lesion. During aiming of the forelimb, the elbow was insufficiently adducted to bring the paw in to the midline, and as a result the forepaw was not aligned with the rat's mouth as the paw was advanced through the aperture. Additionally, the paw was only partially pronated over the food pellet before the grasp was effected. Finally, the forepaw was not supinated independently, either to retract the paw back through the aperture or to bring the food pellet to the rat's mouth. Thus, although the dorsal column-lesioned rats regained the ability to use their affected forelimbs to retrieve food pellets, they did not recover the normal range of movement but rather were able to effect adaptive movements to replace the compromised reaching elements.

The present results also indicate that using an endpoint measurement as the indicator of functional recovery in a complex behavioral task such as skilled forelimb use is insufficient. An examination of the movements used to successfully retrieve pellets after dorsal column lesions revealed that rats used abnormal rotatory body movements to compensate for the forelimb movements they were unable to make. Abnormal rotation of the head and neck and dropping of the ipsilateral shoulder were the most commonly observed compensatory body movements after surgery. Thus, direct observations should be used to supplement endpoint measures.

Severe proprioceptive deficits and impairments in distal forelimb use result from damage to primary afferent fibers in humans (Rothwell et al., 1982; Sanes et al., 1985; Nathan et al., 1986), especially in the absence of vision. However, in nonhuman primates, proprioceptive deficits caused by dorsal column lesions have been reported to be more subtle (Glendinning et al., 1992) and may require more sensitive measurements to be detected (Glendinning and Vierck, 1993). Dorsal column lesions seem to impair primates' abilities to sense spatial (Vierck et al., 1983), temporal (Vierck et al., 1985; Makous et al., 1996), and differential mechanoreceptive (Vierck, 1977) properties of somatosensory stimuli. Thus, precision grasping of small objects is perturbed by dorsal column lesions (Leonard et al., 1992) because of an inability to adjust digit positions (Glendinning et al., 1993) and produce independent multiarticulated digit movements (Cooper et al., 1993). Behavioral deficits have been reported to be less subtle in cats, however. Dubrovsky et al. (1971) trained cats to jump to grasp meat on a rotating wheel and observed behavior that suggested impairments in the planning and execution of this "predator-like" act.

The analysis of the contributions of the dorsal columns to reaching in the rat are of special interest, because rat skilled movements are guided by olfaction and not vision, as in primates and cats, and rat digit movements are not as well developed as those of primates. Additionally, rat spinal cord anatomy is different from cats and primates (e.g., the pyramidal tract is located dorsomedially, beneath the dorsal column and not in the lateral columns). Nevertheless, our behavioral analysis indicated that rats display deficits that are very similar to those of cats and primates. Although they had only transient deficits in reaching success, an analysis of their body, limb, and paw movements revealed persistent abnormalities. These abnormalities appear to include impairments in the synergistic use of body, limb, and paw movements, comparable to the whole-body predatory-like acts (Dubrovsky et al., 1971) or reaching movements (Alstermark et al., 1981, 1987) in the cat and in the use of the wrist and digit segments by primates (Leonard et al., 1992; Cooper et al., 1993). Thus, the novel contribution of the present paper includes not only the finding that dorsal column lesions affect skilled reaching in the rat but also that the impairments described previously for whole-body movements in cats and hand movements in primates extend to skilled limb movements in the rat.

It is likely that a loss of input to the corticospinal system contributed to reaching deficits in the dorsal column lesion group; however, in the absence of the dorsal columns there are a number of pathways that could subserve limb guidance. The spinothalamic tract (Giesler et al., 1981) and several spinoreticular tracts (Tracey, 1995) ascend in the ventrolateral part of the spinal cord and so would be unaffected by any of the lesions in the present study. Spinothalamic axons terminate within ventrobasal (Giesler et al., 1979; Peschanski et al., 1983), posterior (Lund and Webster, 1967; Ledoux et al., 1987), and intralaminar (Giesler et al., 1979) nuclei of the thalamus, whereas spinoreticular axons pri- 
marily terminate in reticular nuclei of the pons and medulla; however, some of these axons also send collaterals to the thalamus (Kevetter and Willis, 1983). Spinocervical axons also ascend within the dorsolateral fasciculus and terminate in the lateral cervical nucleus (Baker and Giesler, 1984). The rat thus may be able to compensate for the loss of dorsal column sensory input because afferent information from the forelimb reaches the brain by a number of other convergent neural pathways, as it does in primates (Brinkman et al., 1978).

We observed that dorsolateral lesions, which damaged the dorsolateral fasciculus and parts of dorsal horn layers I-V, caused transient decrements in pellet retrieval success and persistent deficits in arpeggio and other reaching movements. Dorsolateral lesions probably also damaged lateral corticospinal projections, for although the corticospinal tract is located medially and was largely spared by our lesions, those corticospinal fibers destined for the cervical spinal cord leave the main tract after the pyramidal decussation and descend more laterally to their targets (Valverde, 1966). Thus, the persistent abnormal reaching movements made after dorsolateral lesions could be caused by damage to corticospinal fibers or to one or more of these other lateral structures. Larger combined lesions damaged sensory fibers in the dorsal column in addition to damaging the dorsolateral fasciculus and dorsal horn, the spinocervical tract, spinocervical nucleus, and intersegmental fibers. These lesions may also have deafferented C2-C4 interneurons, which contribute to forelimb control in the cat (Alstermark et al., 1981, 1987). The combined lesion group's lack of recovery of reaching skills may have been caused by the multiplicative effect of damage to dorsal column fibers in addition to damage to one or more of the lateral structures mentioned.

The use of high-speed video recording techniques in this study also revealed abnormal behaviors resulting from dorsal column sensory lesion that closely resemble some behavioral sequelae of pyramidal tract and red nucleus lesions. For example, after both lesions there were impairments in synergistic features of the reaching movement, and the aiming movement (in which the elbow is brought to the midline) was lost. Additionally, after dorsal column lesions, rats effected fewer manual searches and used a rapid grasp, rather than an arpeggio movement, as do rats with red nucleus lesions. These similarities in dorsal columnlesioned and pyramidal- or rubral-lesioned rats suggest that dorsal column afferent input contributes significantly to cortical and rubral motor control in the rat, as has been proposed in the cat (Rathelot and Padel, 1997) and in primates (Leonard et al., 1992). Thus, a dorsal column lesion would cause partial deafferentation of red nucleus as well as basilar pontine gray (Kosinski et al., 1986) and somatosensory cortex.

Schrimsher and Reier (1993) also reported that lesions of primary afferent axons in the rat cause changes in the movements used to grasp food pellets. Data from the present experiment did not confirm the former study's report that dorsal column lesions prevent normal spreading and closure of the digits during reaches, nor did we observe consistent forelimb misdirection after dorsal column lesions. These discrepant findings are most likely attributable to differences in lesion parameters and the data gathering techniques used.

In conclusion, this study shows that the rat retains a remarkable ability to compensate for damage to major sensory fibers. Thus, in addition to clarifying the contribution of the dorsal columns to skilled reaching in the rat, the present results emphasize the importance of using detailed behavioral analyses to accompany endpoint measurements. These behavioral and high-speed filming methods can be usefully applied to the study of recovery and regeneration after dorsal column (Li and Raisman, 1994) or other spinal cord lesions (Li and Raisman, 1995; Li et al., 1997; Diener and Bregman, 1998a,b).

\section{REFERENCES}

Alstermark B, Lundberg A, Norrsell U, Sybirska E (1981) Integration in descending motor pathways controlling the forelimb in the cat. 9. Differential behavioural defects after spinal cord lesions interrupting defined pathways from higher centres to motoneurones. Exp Brain Res 42:299-318

Alstermark B, Lundberg A, Pettersson LG, Tantisira B, Walkowska M (1987) Motor recovery after serial spinal cord lesions of defined descending pathways in cats. Neurosci Res 5:68-73.

Arvidsson J, Pfaller K (1990) Central projections of C4-C8 dorsal root ganglia in the rat studied by anterograde transport of WGA-HRP. J Comp Neurol 292:349-362.

Baker ML, Giesler GJ (1984) Anatomical studies of the spinocervical tract of the rat. Somatosens Mot Res 2:1-18.

Brácha V, Zhuravin IA, Bures J (1990) The reaching reaction in the rat: a part of the digging pattern? Behav Brain Res 36:53-64.

Bregman BS, McAtee M, Dai HN, Kuhn PL (1997) Neurotrophic factors increase axonal growth after spinal cord injury and transplantation in the adult rat. Exp Neurol 148:475-494.

Brinkman J, Bush BM, Porter R (1978) Deficient influence of peripheral stimuli on precentral neurones in monkeys with dorsal column lesions. J Physiol (Lond) 276:27-48.

Castro AJ (1972) The effects of cortical ablations on digital usage in the rat. Brain Res 37:173-185.

Castro AJ, Hogan TP, Sorensen JC, Klausen BS, Danielsen EH, Zimmer J, Neafsey EJ (1991) Heterotopic neocortical transplants. An anatomical and electrophysiological analysis of host projections to occipital cortical grafts placed into sensorimotor cortical lesions made in newborn rats. Brain Res Dev Brain Res 58:231-236.

Cheng H, Cao Y, Olson L (1996) Spinal cord repair in adult paraplegic rats: partial restoration of hind limb function. Science 273:510-513.

Christensen MD, Hulsebosch CE (1997) Spinal cord injury and antiNGF treatment results in changes in CGRP density and distribution in the dorsal horn in the rat. Exp Neurol 147:463-475.

Cooper BY, Glendinning DS, Vierck CJ (1993) Finger movement deficits in the stumptail macaque following lesions of the fasciculus cuneatus. Somatosens Mot Res 10:17-29.

Diener PS, Bregman BS (1998a) Fetal spinal cord transplants support the development of target reaching and coordinated postural adjustments after neonatal cervical spinal cord injury. J Neurosci 18:763-778.

Diener PS, Bregman BS (1998b) Fetal spinal cord transplants support growth of supraspinal and segmental projections after cervical spinal cord hemisection in the neonatal rat. J Neurosci 18:779-793.

Dubrovsky B, Davelaar E, Garcia-Rill E (1971) The role of dorsal columns in serial order acts. Exp Neurol 33:93-102.

Eshkol N, Wachman A (1958) Movement notation. London: Weidenfeld and Nicholson.

Ferguson GA (1971) Statistical analysis in psychology and education, Ed 3. New York: McGraw-Hill.

Galea MP, Darian-Smith I (1997) Manual dexterity and corticospinal connectivity following unilateral section of the cervical spinal cord in the macaque monkey. J Comp Neurol 381:307-319.

Giesler GJ, Menetrey D, Basbaum AI (1979) Differential origins of spinothalamic tract projections to medial and lateral thalamus in the rat. J Comp Neurol 184:107-126.

Giesler GJ, Spiel HR, Willis WD (1981) Organization of spinothalamic tract axons within the rat spinal cord. J Comp Neurol 195:243-252.

Glendinning DS, Vierck CJ (1993) Lack of a proprioceptive deficit after dorsal column lesions in monkeys. Neurology 43:363-366.

Glendinning DS, Cooper BY, Vierck CJ, Leonard CM (1992) Altered precision grasping in stumptail macaques after fasciculus cuneatus lesions. Somatosens Mot Res 9:61-73.

Glendinning DS, Vierck CJ, Cooper BY (1993) The effect of fasciculus cuneatus lesions on finger positioning and long-latency reflexes in monkeys. Exp Brain Res 93:104-116.

Gordon J, Ghilardi MF, Ghez C (1995) Impairments of reaching movements in patients without proprioception. I. Spatial errors. J Neurophysiol 73:347-360. 
Keirstead HS, Hughes HC, Blakemore WF (1998) A quantifiable model of axonal regeneration in the demyelinated adult rat spinal cord. Exp Neurol 151:303-313.

Kevetter GA, Willis WD (1983) Collaterals of spinothalamic cells in the rat. J Comp Neurol 215:453-464.

Kosinski RJ, Neafsey EJ, Castro AJ (1986) A comparative topographical analysis of dorsal column nuclear and cerebral cortical projections to the basilar pontine gray in rats. J Comp Neurol 244:163-173.

Kosinski RJ, Neafsey EJ, Castro AJ (1987) Remodeling of dorsal column nuclear efferents to the basilar pontine gray after cortical ablations in newborn rats. Brain Res 406:302-307.

Ledoux JE, Ruggiero DA, Forest R, Stornetta R, Reis DJ (1987) Topographic organization of convergent projections to the thalamus from the inferior colliculus and spinal cord in the rat. J Comp Neurol 264:123-146.

Leonard CM, Glendinning DS, Wilfong T, Cooper BY, Vierck CJ (1992) Alterations of natural hand movements after interruption of fasciculus cuneatus in the macaque. Somatosens Mot Res 9:75-89.

Li Y, Raisman G (1994) Schwann cells induce sprouting in motor and sensory axons in the adult rat spinal cord. J Neurosci 14:4050-4063.

Li Y, Raisman G (1995) Sprouts from cut corticospinal axons persist in the presence of astrocytic scarring in long-term lesions of the adult rat spinal cord. Exp Neurol 134:102-111.

Li Y, Field PM, Raisman G (1997) Repair of adult rat corticospinal tract by transplants of olfactory ensheathing cells. Science 277:2000-2002.

Lund RD, Webster KE (1967) Thalamic afferents from the spinal cord and trigeminal nuclei. An experimental anatomical study in the rat. J Comp Neurol 130:313-328.

Makous JC, Friedman RM, Vierck CJ (1996) Effects of a dorsal column lesion on temporal processing within the somatosensory system of primates. Exp Brain Res 112:253-267.

Nathan PW, Smith MC, Cook AW (1986) Sensory effects in man of lesions of the posterior columns and of some other afferent pathways. Brain 109:1003-1041.

Neafsey EJ, Sorensen JC, Tonder N, Castro AJ (1989) Fetal cortical transplants into neonatal rats respond to thalamic and peripheral stimulation in the adult. An electrophysiological study of single-unit activity. Brain Res 493:33-40.

Paxinos G, Watson C (1997) The rat brain in stereotaxic coordinates, Ed 3. Orlando, FL: Academic.

Peschanski M, Mantyh PW, Besson JM (1983) Spinal afferents to the ventrobasal thalamic complex in the rat: an anatomical study using wheat-germ agglutinin conjugated to horseradish peroxidase. Brain Res 278:240-244.

Rapalino O, Lazarov-Spiegler O, Agranov E, Velan GJ, Yoles E, Fraidakis M, Solomon A, Gepstein R, Katz A, Belkin M, Hadani M, Schwartz M (1998) Implantation of stimulated homologous macrophages results in partial recovery of paraplegic rats. Nat Med $4: 814-821$

Rathelot JA, Padel Y (1997) Ascending spinal influences on rubrospinal cells in the cat. Exp Brain Res 116:326-340.

Rothwell JC, Traub MM, Day BL, Obeso JA, Thomas PK, Marsden CD (1982) Manual motor performance in a deafferented man. Brain 105:515-542.

Saling M, Sitarova T, Vejsada R, Hnik P (1992) Reaching behavior in the rat: absence of forelimb peripheral input. Physiol Behav 51:1151-1156.

Saling M, Sitarova T, Zlatos J (1996) Adaptive behavioral reactions of reaching in rats following discrete somatosensorimotor cortex lesions. Physiol Behav 59:255-263.

Sanes JN, Mauritz KH, Dalakas MC, Evarts EV (1985) Motor control in humans with large-fiber sensory neuropathy. Hum Neurobiol 4:101-114.

Schallert T, Lindner MD (1990) Rescuing neurons from trans-synaptic degeneration after brain damage: helpful, harmful, or neutral in recovery of function? Can J Psychol 44:276-292.
Schrimsher GW, Reier PJ (1992) Forelimb motor performance following cervical spinal cord contusion injury in the rat. Exp Neurol 117:287-298.

Schrimsher GW, Reier PJ (1993) Forelimb motor performance following dorsal column, dorsolateral funiculi, or ventrolateral funiculi lesions of the cervical spinal cord in the rat. Exp Neurol 120:264-276.

Schwab ME, Brosamle C (1997) Regeneration of lesioned corticospinal tract fibers in the adult rat spinal cord under experimental conditions. Spinal Cord 35:469-473.

Tracey DJ (1995) Ascending and descending pathways in the spinal cord. In: The rat nervous system, Ed 2 (Paxinos G, ed), pp 67-80. New York: Academic.

Valverde F (1966) The pyramidal tract in rodents. A study of its relations with the posterior column nuclei, dorsolateral reticular formation of the medulla oblongata, and cervical spinal cord (Golgi and electron microscopic observations). Z Zellforsch 71:297-363.

Vierck CJ (1977) Absolute and differential sensitivities to touch stimuli after spinal cord lesions in monkeys. Brain Res 134:529-539.

Vierck CJ (1978) Comparison of forelimb and hindlimb motor deficits following dorsal column section in monkeys. Brain Res 146:279-294.

Vierck CJ, Cohen RH, Cooper BY (1983) Effects of spinal tractotomy on spatial sequence recognition in macaques. J Neurosci 3:280-290.

Vierck CJ, Cohen RH, Cooper BY (1985) Effects of spinal lesions on temporal resolution of cutaneous sensations. Somatosens Mot Res 3:45-56.

Whishaw IQ, Gorny B (1994) Arpeggio and fractionated digit movements used in prehension by rats. Behav Brain Res 60:15-24.

Whishaw IQ, Gorny B (1996) Does the red nucleus provide the tonic support against which fractionated movements occur? A study on forepaw movements used in skilled reaching by the rat. Behav Brain Res 74:79-90.

Whishaw IQ, Pellis SM (1990) The structure of skilled forelimb reaching in the rat: a proximally driven movement with a single distal rotatory component. Behav Brain Res 41:49-59.

Whishaw IQ, Tomie J (1989) Olfaction directs skilled forelimb reaching in the rat. Behav Brain Res 32:11-21.

Whishaw IQ, O'Connor WT, Dunnett SB (1986) The contributions of motor cortex, nigrostriatal dopamine and caudate-putamen to skilled forelimb use in the rat. Brain 109:805-843.

Whishaw IQ, Pellis SM, Gorny B, Pellis VC (1991) The impairments in reaching and the movements of compensation in rats with motor cortex lesions: an endpoint, video recording, and movement notation analysis. Behav Brain Res 42:77-91.

Whishaw IQ, Dringenberg HC, Pellis SM (1992a) Spontaneous forelimb grasping in free feeding by rats: motor cortex aids limb and digit positioning. Behav Brain Res 48:113-125.

Whishaw IQ, Pellis SM, Pellis VC (1992b) A behavioral study of the contributions of cells and fibers of passage in the red nucleus of the rat to postural righting, skilled movements, and learning. Behav Brain Res 52:29-44.

Whishaw IQ, Pellis SM, Gorny B, Kolb B, Tetzlaff W (1993) Proximal and distal impairments in rat forelimb use in reaching follow unilateral pyramidal tract lesions. Behav Brain Res 56:59-76.

Whishaw IQ, Gorny B, Sarna J (1998) Paw and limb use in skilled and spontaneous reaching after pyramidal tract, red nucleus and combined lesions in the rat: behavioral and anatomical dissociations. Behav Brain Res 93:167-183.

Winer BJ (1962) Statistical principles in experimental design. New York: McGraw-Hill.

Z'Graggen WJ, Metz GA, Kartje GL, Thallmair M, Schwab ME (1998) Functional recovery and enhanced corticofugal plasticity after unilateral pyramidal tract lesion and blockade of myelin-associated neurite growth inhibitors in adult rats. J Neurosci 18:4744-4757. 